\title{
Music as a Tool for Self-Realization in Chinese Culture: Based on the Practice of Playing the Guqin
}

\author{
Rafał Mazur \\ Jagiellonian University, Kraków, Poland
}

\begin{abstract}
Music has always held an important place in Chinese culture and it has been deeply related to philosophy for ages. In fact, one could say it played a key role in creating Chinese culture and civilisation. It could be assumed that one of the most important concepts of this culture - the Harmony — has its roots in music-making practice and musical terminology. Music was very strongly related to the official social ideology/philosophy of the empire, the Confucianism. As an integral part of the rituals, it became one of the elements ensuring social order. Besides its social/global function, music was an issue of great importance in the practice of achieving one's personal excellence. There is a strong correlation between music and the Chinese idea of a sage, which in the Middle Kingdom is associated with the sense of hearing (not with sight, as it is in the Mediterranean tradition). The musical instrument guqin became an inalienable attribute of a sage and the practice of playing this instrument became a way to wisdom, allowing to improve one's cognition and action. This paper will present the relations between playing the qin, philosophy, and learning wisdom.
\end{abstract}

Keywords: Chinese philosophy, Chinese aesthetics, philosophy of guqin, Chinese art, Chinese music

\section{Introduction}

Assumption that knowledge is a result of cognition is in fact a truism. In most of the cultures created by humans, it is believed that if you want to know something, you need to cognize it first. Since the ancient times, the Europeans have distinguished the knowledge gained through sensual observation from the one acquired by a strictly intellectual process. According to some philosophers (starting from Plato), there is a reality that is not sensual, that can be perceived only with mind. Objects of such reality are intelligible, i.e., accessible exclusively to the intellect. One of the first (and the best) examples of this theory is the world of Plato's ideas. However, other ancient conception, expressed by the Aristotle's phrase "nihil est in intellectu quod non prius fuerit in sensu" and widely spread by St Thomas, regards the important role of the senses in the cognition process. In other words, without the sensual cognition, any purely intellectual speculation may lead you astray.

Basically, most of intellectuals and philosophers in China, members of the wenren (see Appendix) circle, i.e., educated social elite shared Aristotle's point of view. But there is also one important feature of Chinese philosophy worth focusing on. Namely, since the classic period, since the ancient times Chinese philosophers of all schools, especially thinkers considered nowadays the representatives of Daoist school, clearly divided knowledge understood as declarative, positive knowledge from wisdom, which is closely related to the Chinese philosophical tradition. The latter was always highly appreciated in China. The former was not underestimated 
in any way, but it was not necessarily leading to the latter. In case of the Daoists, however, it is believed that knowledge can be an obstacle in reaching wisdom - and those believe can be found in the early classic books such as Daodejing (see Appendix) (n.d.) and Nanhua Zhenjing (see Appendix) (n.d.).

According to the tradition of Chinese philosophy its function is not increase of positive knowledge (by positive knowledge I mean informations regarding matters of fact), but the elevation of the mind - a reaching out for what is beyond the present actual world, and for the values that are higher than the moral ones. [...] In the tradition of Chinese philosophy there is a distinction between working on learning and working on Tao (the Way). The purpose of the former is what I call increase of positive knowledge, that of the latter is the elevation of the mind. (Fung, 1966, p.5)

\section{Chinese Wisdom}

Chinese wisdom zhi (see Appendix), described in the Daoist and Confucian texts, the main characteristic of a sage, is not associated with theoretical knowledge, but with practice. This regards knowledge/wisdom related to the most outstanding manifestations of Chinese philosophy. To give an example: the theory of wisdom constructed by Feng Qi (1915-1995), which

he understood as knowledge of Dao as the fundamental principle of the universe and of human life. Wisdom found its application in our cognitive and practical activities and in our moral cultivation. Philosophers had the task of transforming knowledge, which requires an attachment to object and the self, into wisdom, which sees reality as a whole without such attachments. This transformation came through the sudden enlightenment of intellectual intuition and moved from the realm of nameable to the realm of unnameable. (Cheng \& Bunnin, 2002, p. 10)

Also worth noting the statement of the eminent Confucianist Zhu Xi (1130-1200) advised his students to check the knowledge they learn from books by using it in practice (Tu, 1989). Whereas Zhuangzi made a clear evaluation, expressing explicitly (in numerous fragments of his work Nanhua Zhenjing) a belief that wisdom is superior to knowledge. This opinion is stated very clearly in the parable of the prince Huan and the wheelwright Bian (Zhuangzi, 13.9). However, referring to the questions raised in this fragment, the wisdom also demanded cognition, particularly because, as Zhuangzi says, it was related to action and experience. Exploring, observing the world with senses seems to be the key to gaining wisdom, according to Chinese philosophers. According to contemporary researchers, such as Karyn L. Lai and Chung-yin Cheng the whole Chinese philosophical tradition rooted in studying and commenting Yijing (see Appendix) "emphasizes the importance of being observant of the world around us (guan)" (Lai, 2007, p. 83). Chung-yin even mentions "observational origins of the Yijing" (Lai, 2007, p. 95). In other words, the Chinese cognitive schema, culminating in wisdom, is based on sensory observation.

\section{The Sage}

It is important in context of this paper's subject that the above-mentioned wisdom is a feature of a sage, Chinese anthropological ideal. The Far Eastern wisdom is far from being a certain state that one strives for, then reaches and remains blissfully wise. The wisdom of a Chinese sage consists in making an effort, a continuous effort of self-cultivation; in practising a certain specific way of action, regardless of the nature of that action. Zhuangzi describes this practice exemplified by different crafts. You can strive for wisdom being a butcher, a cook, or a swimmer, producing chime stands, catching cicadas with a stick or dedicating yourself to painting. Wisdom is an ability to follow, in accordance with Dao, the transformations of reality. In other words, one who acts in the world in accordance with the transformations of this world is the real sage. Despite its appearance, it is not a simple matter, for it requires a lot from the self-cultivated individual: deep perception 
and thorough observation guan (see Appendix) that is capable of overcoming the limitations emerging from the culture-specific cognitive structures, structures that play an extremely important role from the operational point of view after all. The Chinese called structuralized mind the cheng xin (see Appendix), and a sage was able to get rid of those structures and had the access to wu xin (see Appendix), which is "no-mind". Thanks to this state of mind he could perceive the world in its continuously changing form, because he did not get attached to any particular state of this world, as he did not distinguish any of them. For him the world was a process, not a state. Zhuangzi describes it the following way:

When the perfect man employs his mind, it is a mirror. It conducts nothing and anticipates nothing; it responds to (what is before it), but does not retain it. Thus he is able to deal successfully with all things, and injures none. (Zhuangzi, 7.6)

\section{Music and Philosophy}

And what is the role of music in the Chinese context, in relation to all the above-mentioned issues? One could say with no doubts that music holds an extremely important place in Chinese culture. In fact, the way music is treated in China is incomparable to any other culture. Obviously, this situation was also reflected in philosophy. Music has been a subject of philosophical reflection since the very beginning of ancient philosophical practice in China. It could even state that it has been given a very important and prominent place in this practice.

Interestingly, music received more attention that other arts in ancient treatises such as Yue ji (Annotations on music), Li ji (Annotations on rites), Lu shi chunqiu (The spring and autumn annals of Mr. Lu), and Fengsu tongyi (Popular pervasive ways). Discussions of other arts also often involve music. Any discussion of ci (poetry) will not be complete without music, since ci was actually written to music and to be sung. In painting, too, numerous of works through the ages have featured the qin (7-string zither now often called guqin). Walter Pater's famous dictum, "All art constantly aspires towards the condition of music", certainly holds true in many respects. (Ho, 1997, p. 36)

As Kenneth DeWoskin (1982) proved, aesthetic terminology of the Confucian cultural area emerges from musical terminology. The author also pointed out that one of the most important concepts of Chinese philosophy, i.e., Harmony, which is still considered one of the main culture-forming concepts in China, comes from musical terminology and originally it meant "harmony of tones" (DeWoskin, 1982). The relations between the music, ethics, and social philosophy are also of great importance. Confucius and his followers, such as Xun $\mathrm{Zi}$, considered music the best tool of governance and bringing about social order. It was also believed that both music-making and listening to music have a remarkable impact on character formation; therefore music was included by Confucius in the Six Arts that should be studied by each noble man. One who entertained himself with Six Arts was resembling the stone "as you cut and then file, as you carve and then polish" (The Analects, 1.15).

However, there is a much deeper relation between Chinese culture (including philosophy) and sound itself, regarding the linguistic world view in Chinese culture and philosophy: It can be found by analyzing the character sheng-Sage (see Appendix). One of this character's components is the radical er (see Appendix), that is "ear". As DeWoskin (1982) demonstrates in his analysis, er is a component of many characters referring to cognition, understanding, smartness, etc.. Moreover, the character signifying "sage" is a homonym for the character meaning "sound". One can find 
the ear radical (erh 耳 no. 128) in both sheng: sage and sheng 声: sound. The same radical is found in ts'ung 聪, a word that evolved into the contemporary term for perspicacity from the original sense of good hearing or an acute ear. (DeWoskin, 1982, p. 33)

According to DeWoskin, this indicates that the hierarchy of the senses in China was different than in Europe. While in the Mediterranean cultural area cognition was based on the visual data coming from the hegemony of vision (which is also indicated by the etymological analysis of the terms vision, wisdom, wise, etc.), in China hearing was/is the sense playing the most important role in cognition. These differences in prioritising sensory signals have influenced the formation of mental cognitive structures, hence the whole world view and conceptual structures used to describe (and also perceive) reality. The recent philosophical and aesthetic reflection on sound art explores these differences between the world view based on sight and the one based on hearing. Basically, it refers to the idea that the world one sees consists of unalterable immobile objects. And even if there are no such objects in the real world (which has been known for a relatively short time), the true objects have to be so, because only then a man can be confident about his cognition. That world view is a basis for the theory of Idea, substance and essence and hence the theory of Truth - unchanging, therefore always real.

Unlike the sight, human hearing instantly informs about fluid and changing nature of reality. One cannot stop the sound; what people hear, they hear as existing in motion. The sound does not "stand still", it keeps attenuating, changing its form. Exploring the world with one's ears one get a direct information about its processual nature. Christoph Cox (2014), an expert in sound art philosophy, says: "Art is not the result but the process, which is captured more fully through the temporality of audio than by the inert visual thing" (p. 97), and his opinion on art may be applicable to the whole reality. Contemporary science, particularly physical chemistry and life sciences, perceives the world in processual and organicistic categories, paying attention to continuous movement of reality and to its constant change. "Sound $[\ldots]$ negates stability through the force of sensory experience. Listening's focus on the dynamic nature of things renders the perceptual object unstable, fluid and ephemeral: unsettling what is through a world of sonic phenomena and audible spirits" (Voegelin, 2011, p. 12).

\section{The Sage and the Sound}

And that is the world described in the crucial, in terms of culture forming, Chinese book, namely Yijing. Its importance in China is comparable to the role that the Bible plays in Europe or the Vedas in India. In other words, these books create the world view and the tools for understanding that world. The Yijing presents the world as a continuous motion, motion of transformations. There are no stable, immobile objects of unchanging nature, and that's why there has never been a theory of substance or essence in classical Chinese philosophy. There is, however, a conception of qi (see Appendix): the most subtle, unformed, immeasurable, and sensually imperceptible layer of reality that remains in perpetual motion, concentrating and attenuating all the time. The qi movement was the basis for the conception of the yin-yang transformation, and consequently, for the conception that the whole reality is undergoing continuous transformation. This cosmological/metaphysical conception has a lot in common with the world view perceived with the sense of hearing. It is an image of world-process that cannot be captured in a fixed framework, just the same way the sound cannot be. The $q i$ itself, on which the conception of world in transformation is based, seems to have characteristics similar to the sound: It is in perpetual motion, it has no stable form, you cannot capture it and it keeps changing its state of 
matter, just like a sound wave attenuating in space. In other words, the world view created by the Chinese indicates the sense of hearing as a provider of perceived data. It is pointed out very clearly in the above-mentioned conception of a sage exploring the world with his ears. As Xinzhong Yao (2000) says: "The sage 'listens' to the calling of Heaven, 'listens' to the demands of the people, and 'listens' to the 'rhythm' of the natural world [...]" (p. 159). Two important fragments of The Analects, regarding cognition, also prove the "aural" approach to exploring the world. In one of them Confucius, referring to his way as a way of a learning, self-cultivating creature, as penultimate stage, describes what happened after he reached the age of 60: 六十而 耳顺—“At sixty, my ear was an obedient organ for the reception of truth" (The Analects, 2.4). The same fragment was translated by Karyn L. Lai (2007) the following way: "From sixty my ear was attuned" (p. 87). In the other one Confucius says about achieving complete understanding: 子曰：朝闻道，夕死可矣—“The Master said, 'If a man in the morning hear the right way, he may die in the evening without regret"' (The Analects, 4.8). In both of these fragments, a strong emphasis is given on the ability to hear, to hear properly, to get in tune with the world using one's ear (the first fragment). In the second one, it is in fact the greatest/ultimate ability, allowing an early completion of the self-realization process. It is noteworthy that in the second fragment there is a wen 闻 character, which can be translated either as "hear" or "become aware of, knowledge, experience". Also, the radical er is used in this character, in accordance with above-mentioned DeWoskin's conception.

In the early Chinese texts, there are numerous references to the importance of the sense of hearing for a sage.

In Pan Ku's Comprehensive Discussions of Virtue in the White Tiger Hall (Pai-hu-t'ung te-lun), written circa A.D. 80, his discussion of the sage (sheng-jen...) begins with the following paragraph: What is meant by the term sheng in sheng-jen? Sheng: sage is what connect things; it is the Tao; it is sheng: sound, There is nothing to which his Tao does not connect and nothing on which his illumination does not shine. By listening to sounds, he knows the nature of things. [...] And Ying Shao's collection of essays, Penetraiting Popular Ways (Feng-su t'ung-i), provides a functional explanation of the link between the sage and sound: "Sheng: sage is sheng: sound. It bespeaks the fact that the sage hears sounds and understands the nature of things." (DeWoskin, 1982, pp. 32-33)

The fragments quoted above give a picture of a clear connection between the sage and the sounds. Even more important, the subject at issue is the sound, not music. Such distinction has been already made in Western culture. And in the second half of the 20th century, it resulted in the emergence of sound art-an artistic sound statement that broke most of the existing rules of creating music, especially in terms of musical material. A thorough analysis of the difference between music and sound does not fall within the scope of this essay, however, due to the essence of the subject, it should be explained what this difference is about. Music, not only in the European tradition, is an art of choosing sounds and assembling them into certain structures. As a result, those structures, consisting of such elements as melody, harmony, rhythm, phrase, motivic development, etc. are the actual object of interest of musicians and listeners. A person receives those structures in the act of musical perception, observes and evaluates them. This situation is parallel to the Confucian "use of music", which was a tool for influencing the society. In this context, music is expected to affect emotions, in this particular case by soothing anger and bringing peace: firstly to individual minds, and then into interpersonal relations. It acts as a tranquilliser, in accordance with the well-known Western proverb saying that "music has charms to soothe a savage breast". Chinese philosophers were also aware of the fact that music can be used as a stimulant, however, stimulating music was socially undesirable and the effects of listening to it were judged negatively. 
Sound, the material people create music with, established autonomy in Western culture as an art object only in the second half of the 20th century, and it is thanks to John Cage, whose work suggested a new approach to listening: One should listen carefully to the sounds themselves, not only to the structure made of them. Moreover, he suggested listening to the sounds not associated with music: rustles, cracks, ambient noises. He never called himself a composer, but an "organizer of sounds" to distinguish his art from the work of existing music creators. Sound art, having developed dynamically since the Cage's "revolution", focuses particularly on sounds, vibrations, and acoustic resonance in space (due to the subject of this paper, the author refers only to the acoustic aspect of sound art, although the whole phenomenon goes beyond the sound). It embraces the sounds from beyond the narrow group of tones (sounds with definite pitch that were the only musical material used until the early 20th century): sounds created synthetically and the natural ambient sounds, sounds of the sounds cape surrounding human beings.

\section{The Lore of the Guqin}

The author mentioned sound art in order to introduce another aspect of working with sound in the Chinese philosophers' activity. Because, apart from involving music into social issues, working with sound was an element of the sage-philosopher's way. The musical instrument guqin (see Appendix) was one of Confucian scholar's attributes, and the skill of playing it was obligatory for any member of wenren class. Qin (see Appendix) is a phenomenon in itself, it is the oldest solo instrument in the world that has been used continuously for about three thousand years, and, according to the Confucian sources, its invention is imputed to the divine sages, the creators of Chinese civilisation. The construction of this instrument, technical details and number of strings have a deep symbolic meaning, its particular elements have plenty of magical and cosmological references. Qin has been already described in many books and scientific articles. Its history, development, playing techniques, notation, and traditional melodies included in its repertoire have been thoroughly analyzed. To all persons interested in the subject, the author shall allow himself to recommend one of the first books in English that is still a great source of knowledge about the qin and its role in the Chinese intellectual and philosophical community, namely The Lore of the Chinese Lute (2011) of Robert van Gulik.

\section{Art in China}

This paper will focus on the philosophical practice related to the qin, because this issue needs to be clarified. At first sight, the situation seems similar to the one existing in Western culture (which is understandable, for one always tries to match the behavioral strategies observed in the investigated civilization with familiar aspects of one's own civilization). In the European cultural area musical participation was also highly valued, both listening to music and performing. Even in the 19th century, it was believed that an educated, truly cultured person should play some musical instrument at least at an amateur level (usually it was the piano). It was often associated with the assumption that educated social elite ought to develop their sensitivity to be able to perceive beauty, which was considered the aim of art and any creative activity until almost the 20th century. Research suggests, however, that Chinese approach to art, deals with another paradigm of action.

It is related mainly to the difference in understanding what art is what it is for. As the research in the field of comparative aesthetics shows, "in traditional Chinese thought on art [...] the category 'beauty' did not play a significant role" (Pohl, 2006, p. 127). As it is emphasized by Zehou Li, Chinese philosophers were convinced about "the isomorphism between art and nature [...] which is consistent with old Chinese saying that 'art is for 
the molding of the human mind" ( $\mathrm{Li} \&$ Cauvel, 2006, p. 2). Art in China was a human action that imitated nature, or, putting it "more Chinese way", it was an ability to act as nature. It was not about mimesis at all, as opposed to the ancient European theory of art. In other words, it was not about imitating phenomena that existed in nature, but about the creative principle ( $f a$ ), according to which those phenomena were created. The ability to act in accordance with nature, in accordance with the principle of nature, was art. Chinese philosophers found this principle in Yijing, where the essence of creative action is described in the first two hexagrams: Qien (the creative) and Kun (the receptive). Therefore, cognition, allowing to perceive the world in its motion and transformations, must be an important element of this kind of action.

\section{The Qin}

Playing the qin has been attributed to the philosophers since the beginnings of Chinese philosophy. This paper will not describe the instrument's history and its role in ritual music, that is in social ethics-related practices (the work of van Gulik and many other studies concerning this issue are highly recommended for anyone interested in the subject). The attention will focused on the place that playing the qin and the instrument itself held in the philosophers' personal practice, on the link between musical practice and self-realisation, the way of the sage. It is noteworthy, that however social aspect of music is related to Confucian philosophy sensu stricto (i.e., the reflections of Confucius and his outstanding disciples regarding social order), the issues of music-making with the aim of self-realisation, according to van Gulik, have deep roots in Daoism. Daoist philosophy, both Laozi and Zhuangzi, lies at the basis of so-called qin philosophy.

According to the sources of the wenren circle, the qin (van Gulik uses the term "lute") is the oldest truly Chinese instrument.

Literary tradition asserts that original function of the lute was as a solo instrument; as such it was played by its inventor, one of the ancient Chinese mythical Emperors, said to have ruled in or about the third millennium B. C. Some sources say it was the Emperor Fu Hsi, others Shen-nung, others Shun. [...] "Fu Hsi made a lute, whereby to restrain falsehood, to guard the heart against low desires, that man might be cultivated and his nature regulated, to make man return to what is truly heavenly in him." [...] "Lute means restraining. With this instrument licentiousness and falsehood are restrained, and the human heart is rectified." (van Gulik, 2011, p. 6)

It worth mentioning here, that the Chinese use the same character for "heart" and "mind", namely xin (see Appendix), that in the present day is translated as "heart-mind". Xin is an emotive-cognitive organ responsible for both cognition and emotions. Chad Hansen (2003) describes it the following way:

The core Chinese concept is xin (the heart-mind). As the translation suggests, Chinese folk psychology lacked a contrast between cognitive and affective states ([representative ideas, cognition, reason, beliefs] versus [desires, motives, emotions, feelings]). The xin guides action, but not via beliefs and desires. It takes input from the world and guides action in light of it. Most thinkers share those core beliefs. (p. 581)

Therefore, the qin has been an emblem of the sage-philosopher since the beginnings of Chinese civilization. As a result, after the wenren class had been established (the times of Han Dynasty), when Confucianism became an official state ideology and the Four Books of Confucius were required reading for civil service examinations, the qin became (together with painting, calligraphy, and Chinese chess wei qi) one of the Four Arts of the Chinese Scholar, occasionally known as the Four Attainments of Pleasure. "The Superior man does not suffer the lute to be separated from him during one single moment" (van Gulik, 2011, p. 43). The instruments became collector's items, they were exposed in the scholars' workrooms; there were 
special editions of poetry about them. And obviously, music was made with them. This musical practice, however, was different from those that are known from Europe or other social classes of the Far East.

\section{Musical Practice as a Self-Realization}

The philosophers were not musicians in a professional sense, however, according to the writings quoted by van Gulik, many of them reached mastery in playing the qin. Nevertheless, most of them were satisfied with ability to play easy traditional tunes, often in simplified versions. Moreover, they did not perform in public, usually they played alone in their studies or in the wilderness - outside the town, in the mountains or in the special private gardens of their own design, arranged to resemble wild nature. There was a meticulous set of rules regarding this instrument: A person from beyond the wenren circle was not allowed even to touch the qin, and participation of non-scholars in musical performances was prohibited too. In other words, it was not a public activity, and the philosophers "deepened its significance, in order to remove it further from ordinary music and to consolidate its position as the treasure house of true music and the only officially recognized musical instrument of the literary class" (van Gulik, 2011, p. 43). They used to play qin music among themselves, claiming that the rest of society was not prepared for reception of this music.

Then who and what was the philosophers' music for, if it was not performed in public? In this regard, to paraphrase a Chinese saying that has been already quoted in this article, "music if for the molding of the human mind". Chinese philosophers used the music as a kind of "vehicle" circulating on the way of the sages. The way that led to harmony with Heaven and Earth, that is with the whole world (the combination of "earth" character and "heaven" character, tiandi means "world" in Chinese). As Zai Yung says in one of his in passage:

The tone of the ch'in is the true tone of heaven and earth. If the right materials are found, they will provide a true instrument for harmonizing heaven and earth. If the right person is found, it can provide him the correct Way for harmonizing heaven and earth. If the exact pitch is found, it will make correct tones for harmonizing heaven and earth. Fu Hsi made the ch'in in order to make perceptible the system of heaven and earth and to harmonize the powers of the spiritual forces. (DeWoskin, 1982, p. 111)

Chinese philosophers believed that the unique sound of the qin (soft, quiet, and attenuating easily, thanks to the strings made of boiled silk threads) is a sound that clears the mind (makes the mind become a mirror-Zhuangzi) and then changes the perception level from differentiated phenomena to undifferentiated unity. Laozi called this unity - bringing to light all the individualised things, but not determined in any way - the Mother of all things, The Great Carpenter or simply Dao. The musical metaphor for Dao in the Daodejing is the "Great Tone has no Sound", Da yin xi sheng, the tone that all the sounding tones emerge from, but that itself has no sound. If it did, it would become just another distinguished, particular tone, whereas it is the source of all tones, hence it cannot sound. This is an attempt to describe with tones the undifferentiated source of phenomena that manifest themselves in the sensually accessible world. Anyone can see the forms of beings in the surrounding reality, but only few can perceive their source-undifferentiated, shapeless an undetermined. The ability to perceive the source and the whole process of determined forms emerging from the source and then going back to it was an exclusive characteristic of a sage. Only he could perceive the world in its shapeless nature, resulting from the eternal motion of transformations. The practice of playing the qin made the sage's mind (directly, by the unusual sound of the instrument and by the way of playing it) capable of meeting the Ultimate Tone that has no sound. In other words, the sage's cognition embraced the whole world, not only its differentiated level. It could also be said that the sage heard the whole world - not only the 
proverbial "five sounds", but also the source they came from. As one can read in the Spring and Autumn Annals of Mr. Lu: "The sage hears the soundless" (DeWoskin, 1982, p. 32).

The very act of playing the qin had a specific form. The melodies chosen by philosophers from the repertoire of this instrument, had exceptionally simple, uncomplicated construction, compared to e.g., pipa music. Qin repertoire was rarely enriched with new pieces-philosophers contented themselves with performing old melodies, in many cases "fabricating" their ancient origin. Van Gulik (2011) described the uniqueness of qin music compared to other instruments repertoire in the following way:

It is easier to describe this music in negative than in positive terms. It may be stated at once that it is not like that of any of the better known stringed instruments to be found in present-day China, as, for instance, the two-stringed violin or erh-hu, the four-stringed mandolin or p'i-pa, or the moon guitar or yueh-ch'in. The music of these instruments being highly melodic, it can be appreciated by anyone who possesses some capacity for musical adaptation. At first hearing their music may seem a little strange, but the ear soon adjusts itself to be quaint chords and unusual movements, and this music is easily understood. The lute, on the contrary, is not too easy to appreciate, chiefly because its music is not primarily melodic. Its beauty lies not so much in the succession of notes as in each separate note in itself. "Painting with sounds" might be a way to describe its essential quality. Each note is an entity in itself, calculated to evoke in the mind of the hearer a special reaction. The timbre being thus of the most utmost importance, there are very great possibilities of modifying the colouring of one and the same tone. (p. 1)

Reading the above-mentioned text, someone used to the European music tradition might find it strange that qin music "is not primarily melodic" and that "its beauty lies not so much in the succession of notes as in each separate note in itself". But taking into consideration the development of sound art, these phrases do not sound strange any more. The author believes that in case of Chinese philosophers' musical practice one deals with abandoning work with sound structures in favor of work with sound-in-itself. (Incidentally, it should be pointed out that contemporary music activities related to qin do not necessarily have much in common with the tradition of described practice. But that is a subject that should be discussed separately). Such operation seems necessary, when one wants not to stimulate the mind with emotions included in the melodies, but rather to free it from emotions. Obviously, the sound works of wenren circle music were not the same as the ones emerging from sound art, but the way philosophers worked with the available sound material, i.e., traditional melodies, consisted not in accurate reproduction of those melodies, but in working with sound and its impact on the mind. It is quite clear that experiencing music in the wenren circle was far from contemplation of Beauty, for, as it was said before, that was not the aim of Chinese art. Consequently, it should be assumed that musical practice was one of the philosophical meditation practices of Chinese philosophers, allowing to reach the wu xin state of mind, thoroughly described by Zhuangzi (mirror-mind, see above), that enabled perceiving the world in the motion of changes and thus joining this motion of changes, that is uniting in harmony with the whole world; uniting with Dao. That ability was a characteristic feature of a sage.

The fact that the profession of music composer had not existed in the Chinese tradition until the early 20th century, i.e., the moment of intensive inter-cultural exchange between East and West, can be an argument for the hypothesis suggested above.

In literati music, qin playing was the all-important activity: it epitomised the essence of Chinese philosophy and aesthetics. People rarely asked who wrote the music, but rather who played it and how it was played. The name of the composer was of secondary importance, while that of performer become more and more important. (Ho, 1997, p. 36)

This indicates an attitude towards music that is quite different from the one of the Western tradition, where 
the composer was/is considered the most important person in regards to creating music. The essence of music is a musical piece you can experience even in its non-sounding form, i.e., through score music reading. You can discuss and evaluate music using the score. It is significant that studying European musical encyclopaedias, textbooks in music history or musical forms, there is plenty of information regarding composers and compositions, details of musical material organization, but nothing about specific performances, that is the sounding realization of musical works. As shown in the quotation above, in China the most important thing was working with sound; composition-related issues were relegated to a secondary position.

In context of the discussed subject, it is equally important to give some thought to the phenomenon of Chinese philosophers playing the one-stringed qin or instruments with no strings at all. As one can see in Chinese writings, such practices were associated with cultivating the way of sage, the way of self-realisation:

Sun Teng, a sage intimately associated with ch'in, refuses to speak with or even acknowledge the presence of a young aspirant who come to study the Way with him. Sun's biography notes that he "loved to read the Changes and play the one-string ch'in" and would only play the one-string ch'in as his guest looked on. In his portraits, the single string of the ch'in is carefully illustrated. The best-known example of a sage who played a non-sounding ch'in is T'ao Yuan-ming, who is reported to have said, "Knowing the significance of what is the ch'in, why labor to bring sound up from its strings?" [...] T'ao is described as owing one very plane ch'in, without any strings at all [...]. (DeWoskin, 1982, p. 144)

The examples above clearly indicate a link between the practice of playing the qin and the philosophical practice of following the way of sage. Of course, described behavior is unusual-most philosophers made music with their regular five-stringed instruments. However, regardless the number of strings and the question if the instrument actually produced any sound or not, the musical practice of Chinese philosophers was an embodiment of their philosophy. It was a continuous effort of following the way of self-realization.

Playing the lute purifies one's nature by banishing low passions, therefore it is a sort of meditation, a means for communicating directly with tao. Its rarefied notes reproduce the "sounds of emptiness", and so the music of the lute tunes the soul of the player in harmony with tao (van Gulik, 2011).

\section{Conclusion}

This paper is an attempt to point out that the music of Confucian philosophers circle (wenren yinyue) requires not only musicological research on repertoire or notation, but also a research in the field of cognition and action. Research on music as a cognitive practice anticipating certain sage-specific way of action, described in e.g., Daoist classics; practice that allows to reach the wuxin state of mind which permits perception of the world in its transformations, in perpetual motion and therefore allows to act in accordance with the changes, to join this motion of the world, to unite with Dao. In classical Daoist writings, such model of action is called wei wu wei, that is "action through non-action, abstinence from action", claimed to be the model of action of the very Dao. "The Dao in its regular course does nothing (for the sake of doing it), and so there is nothing which it does not do" (Laozi, 3). In regard to this subject, it would be undoubtedly interesting to investigate the impact of sound/music on the brain and mind in the practice of mindful meditation that seems to lead to the state of wuxin ("mind as a mirror", described by Zhuangzi). Also, it is worth making researches on the link between Asian shamanic practices and Daoist practices. Certainly, the research on the wenren circle musical practice is very difficult, mainly because of the fact that this social group ceased to exist in 1911. The tradition of Confucian scholars, together with their education model, philosophy, aesthetics, and art practice has disappeared. Nevertheless, the culture that was being formed by educated Confucian scholars for such a long 
time has preserved some thinking structures and action strategies (e.g., in martial arts). Investigating them and combining the results of that investigation with interpretation of Chinese philosophical writings can remarkably expand one's knowledge on the way of sages and will probably enrich one's own culture.

\section{References}

Cheng, C. (2001). On human consciousness in classical Chinese philosophy: Developing onto-hermeneutics of the human person. In New interdisciplinary perspectives in Chinese philosophy (pp. 9-32). Malden/Oxford: Blackwell Publishing.

Cheng, C., \& Bunnin, N. (Ed). (2002). Contemporary Chinese philosophy. Malden/Oxford: Blackwell Publishers Ltd..

Cox, C. (2014). Seeing is not hearing: Synaesthesia, anaesthesia and the audio-visual. In G. Celant (Ed.), Art or sound (pp. 93-98). Venice: Fondazione Prada.

DeWoskin, K. (1982). A song for one or two. Music and the concept of art in early China. Center for Chinese Studies, The Univesity of Michigan.

Fung, Y. (1966). A short history of Chinese philosophy. New York: The Free Press.

Hansen, C. (2003). Philosophy of mind. In A. Cua (Ed.), Encyclopedia of Chinese philosophy (pp. 581-588). New York: Routledge.

Ho, E. (1997). Aesthetic considerations in understanding Chinese literati musical behaviour. British Journal of Ethnomusicology, 6, 35-49.

Lai, K. L. (2007). Understanding change: The interdependent self in its environment. In New interdisciplinary perspectives in Chinese philosophy (pp. 81-99). Malden/Oxford: Blackwell Publishing.

Laozi. (n.d.). Daodejing (J. Legge, Trans.). Retrieved from http://ctext.org/dao-de-jing

Li, Z., \& Cauvel, J. (2006). Four essays of aesthetics. Toward a global view. Lanham: Lexington Books.

Pohl, K. H. (2006). Chinese aesthetic and Kant. In The pursuit of comparative aesthetics (pp. 127-136). Aldershot: Ashgate Publishing Limited.

Tu, W. (1989). Centrality and commonality. An essay on Confucian religiousness. In SUNY series in Chinese philosophy and culture. Albany: State University of New York Press.

Van Gulik, R. H. (2011). The lore of the Chinese lute. Bangkok: Orchid Press.

Voegelin, S. (2011). Listening to noise and silence. Towards a philosophy of sound art. New York/London: Continuum International Publishing Group.

Yao, X. (2000). An introduction to Confucianism. Cambridge/New York: Cambridge University Press.

Zhuangzi. (n.d.). Nanhua Zhenjing (J. Legge, Trans.). Retrieved from http://ctext.org/zhuangzi

\section{Appendix: Chinese Glossary}

cong (ts'ung) 聪

cheng xin 成心

Dao 道

Daodejing 道德经

da yin xi sheng 大音希声

guan 觀

Laozi 老子
Nanhua Zhenjing 南华真经

qi 气

qin 琴

sheng $<$ sage $>$ 圣, trd. 聖

sheng $<$ sound $>$ 声, trd. 聲

tiandi 天地

wei wu wei 为无为 wenren 文人

wenren yinyue 文人音乐

wu xin 无心

xin 心

zhi 智

Zhuangzi 庄子 